\title{
A brief review of fatigue design criteria on offshore wind turbine support structures
}

\author{
P. Mendes, J.A.F.O. Correia, A.M.P. De Jesus
}

CONSTRUCT \& INEGI, University of Porto, Faculty of Engineering, Portugal

pjmendes@fe.up.pt, bttps:/ / orcid.org/0000-0002-8588-4807

jacorreia@fe.up.pt, https://orcid.org/0000-0002-4148-9426

ajesus@fe.up.pt, bttps://orcid.org/0000-0002-1059-715X

B. Ávila, H. Carvalho

Federal University of Minas Gerais, Brazil

biancavieiraavila@gmail.com, bttp://orcid.org/0000-0003-0630-7487

hermes@dees.ufmg.br, bttps://orcid.org/0000-0002-4652-8068

\section{F. Berto}

NTNU - Norwegian University of Science and Technology, Department of Mechanical and Industrial Engineering, Norway filippo.berto@ntnu.no,bttps:/ /orcid.org/0000-0001-9676-9970

\begin{abstract}
In this paper, a brief review of the main fatigue design criteria and some advanced fatigue approaches applied to offshore structures (e.g. offshore wind turbines) are presented. It is extremely important to understand the fatigue phenomenon and how it affects structures since offshore structures are constantly submitted to cyclic loading and corrosive attacks that aggravate the problem. All the influencing factors and approaches used during the design phase are also discussed.
\end{abstract}

KEYWORDS. Fatigue; Life extension; Design codes; Offshore wind turbines; Support structures.

\section{INTRODUCTION}

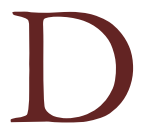
espite taking into consideration the effect of environmental loads, as wind loads, wave loads, current loads, and water levels in the design of offshore wind turbines, the structural breakdown will probably occur due to fatigue damage before its extreme failure from loads [1]. In these structures, Fatigue is related to cyclic loading and continuous dynamic loading, environmental factors such as corrosion can also contribute to a faster collapse. Therefore, the fatigue design of offshore structures is based on the assessment of each individual member, so a fatigue reliability design 
becomes mandatory in offshore tubular joints due to the concentration of stress in the connection region [2]. This analysis should be applied in order to minimize the costs in the useful life of an on- or off-shore tubular member, considering inspections, maintenance, and repairs [3]. Currently, there are many design recommendations, such as the DNVGL [4] and API [5] recommendations, which present estimation methods to assess the damage and estimate the service life due to the fatigue of an offshore tubular member.

Dong et al. [6,7] carried out a fatigue study on multiplanar welded tubular joints on an offshore wind turbine of the Jacket type and the dynamic response of the structure due to wind and wave loads was also evaluated. Dong et al. [7] normalize load histories to ensure that the fatigue design requirements are based on the SN-Palmgren-Miner approach. An important point identified in this work is that the authors also considered an increased rate of corrosion-induced crack growth. Alati et al. [8] presented a comparative study of the fatigue performance in Offshore Wind Turbines (OWT) structures of the Jackets type in waters of intermediate depth. The fatigue behaviour was evaluated in the time domain under a combined stochastic load of wind and wave loads. Yeter et al. [9] performed an analysis of the structural integrity of the support structure in various loading scenarios for different operational modes. The authors used the Weibull distribution of two parameters to adjust the long-term statistical distribution of voltage ranges for critical points of representative environmental conditions in the operating conditions of the wind turbine. Colone et al. [10] investigated the impact of turbulence-induced loads and kinematic wave models in the assessment of fatigue reliability on offshore monopile wind turbines. This research focused on the study of the effects of uncertain marine environments on the distribution of the fatigue load. Biswal and Mehmanparast [11] performed an estimation of the fatigue life in monopile structures and the fatigue damage analysis was performed on the weld joints, using the finite element method. The S-N fatigue design approach and the maximum stress range in the weld were used to determine the fatigue crack life in monopiles.

A study of fatigue assessments in the time domain was carried out by Chian et al. [12], using the Monte Carlo sampling method, in addition to stochastic processes that were considered to simulate wind and wave loads. Peeringa [13], demonstrated that the wave-current interaction must be taken into account for the load calculations of the fatigue project of OWT structures. Teixeira et al. [14] evaluated statistics data on the extrapolation of fatigue loads to the tower and the influence of environmental parameters on short-term damage, a sensitivity analysis was conducted to assess which of the five environmental variables evaluated were most prominent in quantifying the damage uncertainty of the turbine. Horn and Leira [15] investigated the impact on the estimated life of an offshore wind turbine through the introduction of a stochastic model. An incremental damage model of two scales was proposed by Rocher [16], in order to follow the temporal evolution of the damage caused by fatigue.

Fatigue assessments of offshore wind turbine support structures have also been proposed in the literature considering realistic environmental conditions [17], economic-tracking NMPC [18], and a parallel scheme [19].

\section{OFFSHORE STRUCTURE TYPES}

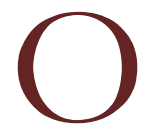

ffshore structures are divided into fixed and floating structures. Inside these two types of structures, there is a different wide of models for platforms. Determining which type of structure fits the best depends on various factors as water depth, role, and functionality $[2,20]$.

\section{Floating structures}

The floating structures may be grouped as Neutrally Buoyant and Positively Buoyant (buoyant is the ability of something to float). The neutrally buoyant structures include Spars, Semi-submersible MODUs (Mobile Offshore Drilling Unit), and FPSs (Floating production systems), Ship-shaped FPSOs (Floating production and storage systems) and Drill-ships. Positively buoyant structures, such as the Tension Leg Platforms (TLPs) and Tethered Buoyant Towers (TBTs) or Buoyant Leg Structures (BLS) are tethered to the seabed and are heavy-restrained.

The sizing of floating structures is dominated by considerations of buoyancy and stability. Topside weight for these structures is more critical than it is for a bottom-founded structure [21]. Some of the examples of floating structures can be seen in Fig. 1.

\section{Fixed structures}

Loads in fixed offshore structures are directly transmitted to the foundation members and these elements are, generally, welded steel tubular members. These platforms have rigid behaviour and must withstand all the dynamic environmental forces. Of the most commonly known types of fixed structures, there are gravity base structures that use their own weight to remain stable when subjected to stresses on the structure, guyed towers but the most common type of offshore platform 
is fixed, pile-supported steel template platform, often called a jacket. For wind turbines, the supporting structures are composed of limbs deep-immersed steel or concrete pipes filled with high-density materials [21].

Monopiles are the most commonly used type of support for wind turbines due to their design simplicity and suitability for shallow waters. Also, they are composed by tubular steel members with huge diameter and thickness. Jacket type structures are usually composed of tubular members interconnected, shaping a tridimensional spacial structure allowing the application of them in higher water depths. Since there are joints in these structures, it is necessary to deepen the studies in this area during the design phase because most of the failures are due to fatigue. [21,23]. Examples of fixed offshore structures are shown in Fig. 2.

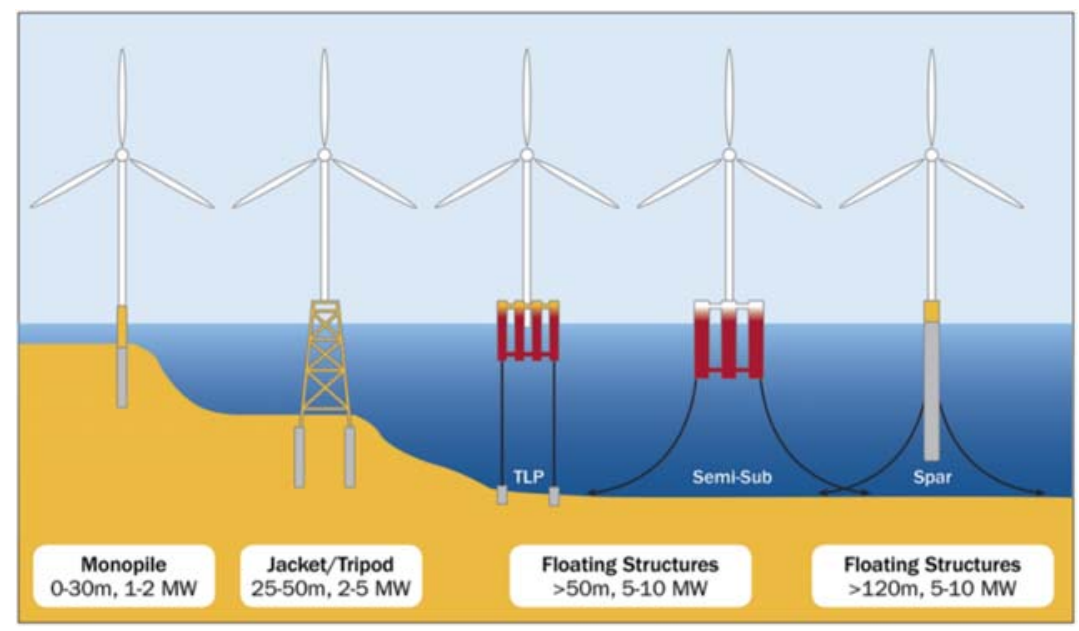

Figure 1: Types of offshore wind turbine foundations [22].

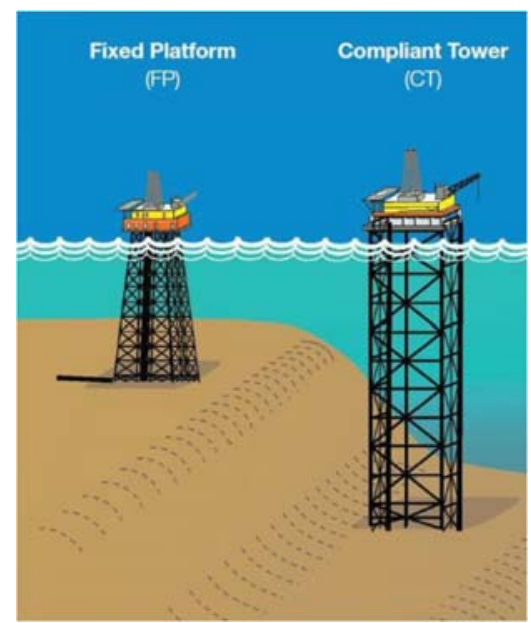

Figure 2: Examples of fixed offshore structures [5].

The design of offshore structures is based on the conditions and environmental aspects in which the structure is submitted. For the static analysis, an offshore structure can be submitted to permanent loads as dead weight and equipments, gravity loads, live loads, and hydrostatic loads. Dynamic loads are, generally, originated by environmental loads: wind loads, wave loads, current loads, ice loads, snow loads, earthquake loads, and other environmental loads. Environmental loads are studied with more detail since the evolution of cracks in these structures are due to then $[2,20,21,23]$.

\section{Wind}

Wind-induced loads are often treated as time-invariant and wind acts in a direction normal to the surface of the structure. In cases of large windswept surface, the frictional forces due to tangential drag must also be considered [24]. The strength of wind, in a circular structural member, acting normal to the member surface is calculated by: 


$$
F_{w}=\frac{1}{2} \rho C_{D} A U_{w}^{2} \sin \alpha
$$

where: $\rho$ is the mass density of air; $U_{w}$ is the wind velocity averaged over a time interval $T$ at a height $z$ meter above the mean water level or onshore ground; $C_{D}$ is the shape coefficient; $A$ is the projected area of the member normal to the direction of the force; and $\alpha$ is the angle between the direction of the wind and the axis of the exposed member or surface. The aerodynamic study in offshore wind turbine structures is of great importance because the marine environment provides winds of greater speed and consistency, less turbulence and less shear which, in addition, are used in this study to evaluate aerodynamic damping, since they are slender structures and, as said, subjected to high wind loads [25]. Liu et al. [26], present an analysis of a model of aerodynamic damping for wind turbine blades and wind turbine blades have been found to undergo significant vibrations and deflections during operation so the aerodynamic damping considerably affects the structural response of the blades. Liu et al. [25] also carried out an analysis that combines aerodynamics, hydrodynamics and structural dynamics of the structure and includes the effects of aerodynamic damping, but this time for the entire wind tower, with the aim for a better understanding of the role of aerodynamic damping during interaction of wind and waves in the structure. In addition, the influence of different methods to calculate aerodynamic damping on the prediction of fatigue loads is studied.

Li et al. [27] investigated the effect of the wind field on power generation and the aerodynamic performance of offshore floating wind turbines and for this purpose, three types of wind fields were studied: a uniform wind field, a constant wind field with shear and a turbulent wind field. It was observed that the final structural and fatigue loads at the blade root were increased by the turbulence of the flow and by the wind shear.

\section{$W$ aves}

Due to the random nature of ocean waves, in height, shape, direction, length, and speed of propagation, the state of the sea is best described in a random wave model. However, waves can take the form of a regular wave. These waves have the characteristics of a period such that each cycle has exactly the same shape. Several theories have been developed to simplify the use of wave calculations. The wave conditions considered in the design of the offshore structures, can be described using deterministic methods or by stochastic methods. In structures with the quasi-static response the use of deterministic regular waves is sufficient but structures with significant dynamic response need more accurate studies, so in this way, stochastic modelling of the sea is more appropriate [21,24].

The linear model, developed by Airy, is the simplest theory of waves and, currently, the most precise for waves of small amplitude [28] (Skjelbreia and Hendrickson, 2011). It is considered that the height of the wave is much shorter than the wave length and the depth of the water. For the Airy wave theory, the waves have sinusoidal shapes, where the free surface profile is described by the formula:

$$
\eta=\frac{H}{2} \cos (k x-\omega t)
$$

where: $H$ is the height of the wave; $k=2 \pi / L$ is the wave number; $L$ is the wave length; $\mathrm{x}$ is the position of the wave; $\omega=2 \pi / \mathrm{T}$ is the wave frequency; $T$ is the wave period; and, $t$ is the instant of a duration of the wave.

In cases where the wave amplitude is not small or for high values of wave inclination, and linear theories do not reach an adequate degree of precision, nonlinear theories are adopted as the theories of Stokes, Cnoidal or Solitary. Stokes' theory assumes that any variation in the $\mathrm{x}$-direction can be represented by the Fourier series, which can be written as disturbance expansions that increase with the wave height [29]. In this way, the wave velocity potential and the wave surface profile can be represented respectively, by the following equations:

$$
\begin{aligned}
& \phi=\sum_{n=1}^{M} b_{n} \phi_{n}(H, T, d) \sin (n(k x-\omega t)) \\
& \eta=\sum_{n=1}^{M} a_{n} f_{n}(H, T, d) \cos (n(k x-\omega t))
\end{aligned}
$$


where: $M$ is the considered order; $b_{n}$ and $a_{n}$ are initially unknown functions that depend on the boundary conditions. Using these series, any order of approximation for Stokes' theory can be obtained, and this one used in the first order is identical to a linear wave [24]. For example, the wave surface profile in second-order theory can be obtained from the equation:

$$
\eta=\frac{H}{2} \cos (k x-\omega t)+\frac{H^{2} \pi}{8 L} \frac{\cosh (k d)}{\sinh ^{3}(k d)}[2+\cosh (2 k d) \cos 2(k x-\omega t)]
$$

Selecting the wave theory applicable to an offshore structure model is an essential step in a hydrodynamic analysis. The nonlinearity of the waves and the depth of the water are two keywords in the hydrodynamic analysis for fixed and floating wind turbines since offshore wind farms are generally implanted in areas of relatively shallow water, where the waves become more non-linear and lead to a considerable increase in hydrodynamic loads [30]. Cheng et al. [31] analysed a numerical model with second-order wave effects for aero-hydrodynamic analysis of floating offshore wind turbines. Marino et al. [32] evaluated the structural response of an offshore wind turbine subjected to two wave models: linear and non-linear, and observed that when the turbine is parked, the linear wave modelling approach significantly underestimates fatigue loads. Stokes' fifth-order model has been used due to good results regarding the actual representation of water particles. Chen et al. [33] used Stoke's fifth-order nonlinear theory to represent regular waves in an analysis of static and dynamic loading behaviour in offshore wind turbines. Li et al. [34] verified the influence of different water depths on the structural behaviour induced by non-linear waves. The effect of wave non-linearity due to the kinematics of non-linear waves was quantified by $\mathrm{Xu}$ et al. [30]. The structural responses of the floating wind turbine were compared when exposed to irregular linear aerial waves and totally non-linear waves.

\section{Morison's Equation}

Morison's equation is applied when it's needed to transform wave kinematics into hydrodynamic forces. Morison's load formula is applied when the $\lambda>5 D$ ratio is met, $\lambda$ is the wave length, and $D$ is the cross-sectional dimension of the member [24]. For fixed structures in waves and currents the hydrodynamic force is calculated according to the equation:

$$
f_{N}(t)=\rho\left(1+C_{A}\right) A \dot{v}+\frac{1}{2} \rho C_{D} D v|v|
$$

where: $v$ is the fluid particle (waves and/or current) velocity $(\mathrm{m} / \mathrm{s}) ; \dot{v}$ is the fluid particle acceleration $\left(\mathrm{m} / \mathrm{s}^{2}\right) ; A$ is the cross-sectional area in $\left(\mathrm{m}^{2}\right) ; D$ is the diameter or typical cross-sectional dimension $(\mathrm{m}) ; \rho$ is the mass density of the fluid $\left(\mathrm{kg} / \mathrm{m}^{3}\right) ; C_{A}$ is the added mass coefficient; and $C_{D}$ is the drag coefficient. Both coefficients, $C_{A}$ and $C_{D}$, vary with the Reynolds number and the Keulegan-Carpenter number.

Other types of loads

Other environmental loads can be studied according to the occurrence and necessity as, current loads due to tides, storms, and atmospheric variations. In places like the artic, where it's expected the presence and formation of ice, the distribution and concentration of ice must be considered. Earthquakes should also be considered if platforms are located in a seismically active zone [24].

\section{ENVIRONMENTAL EFFECTS ON FATIGUE PROJECTS}

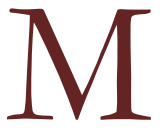

arine environments provide immersed steel structures corrosive attacks that influence directly the performance and the fatigue design of a tubular member. When corrosion appears in a structure, there is a reduction in the effective section area that consequently raises the applied stress levels and decreases the lifespan of the whole structure. The interaction between the corrosive environment and the cyclic mechanical loading generally results in a 
significant increase in the rate of crack growth, as compared to a non-corrosive environment, which further reduces the overall fatigue life [35].

There are two mechanisms associated with the corrosion effects that when started aggravate the initiation process of cracks. In the first mechanism, there is localized corrosion -Pitting-, which constitutes the formation of corrosion pits that act as micro-notches locally increasing the stress level. In the second mechanism, corrosive environments may introduce hydrogen into the metal by the dissociation of hydrogen molecules into atomic hydrogen. Under cyclic loading conditions, the resulting hydrogen embrittlement of the material may accelerate the initiation of surface flaws [35,36,37]. Fig. 3 shows the common pit shapes.

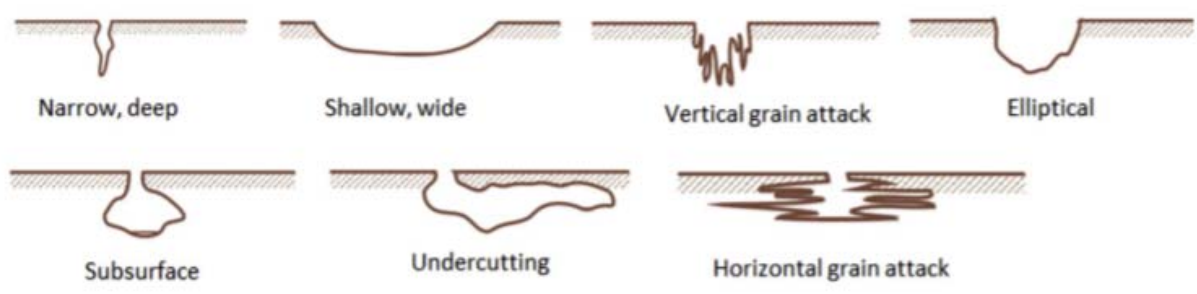

Figure 3: Common pit shapes [37].

\section{FATIGUE DESIGN CRITERIA PRESENT}

ifferent approaches can be used in the fatigue analysis but the decision of which method suits better depends on which structural details need to be considered. The fatigue life evaluation is based on the linear damage hypothesis (Palmgren-Miner's rule) and in the S-N curves presented in the fatigue design recommendations as in DNVGLRP-C203 [4], API [5], etc. [2,20]. An extensive study in a more considerable portion of the structure or a fracture mechanic approach analysis must be done when the crack is going to be fatal and if estimating the fatigue life based on the data of S$\mathrm{N}$ curves becomes insufficient or inappropriate [4]. In this section, the damage accumulation law and global fatigue design S-N curves are presented.

The damage accumulation law called Palmgren-Miner [38] is a common method to estimate the fatigue life of structures submitted to a history of variable loads based on a series of fatigue stresses with constant amplitudes. Palmgren-Miner's rule [38] can be translated into Eqn. 7:

$$
D=\sum_{i=1}^{k} \frac{n_{i}}{N_{i}}=\frac{1}{\bar{a}} \sum_{i=1}^{k} n_{i} \cdot\left(\Delta \sigma_{i}\right)^{m} \leq \eta
$$

where: $D$ is the cumulative fatigue damage; $n_{i}$ is the number of cycles the structural detail endures at stress range, $\Delta \sigma_{i} ; N_{i}$ is the number of cycles to failure at stress range, $\Delta \sigma_{i} ; i$ is the number of considered stress range intervals; $k$ is the number of considered stress range intervals; $\bar{a}$ is the intercept of the design $\mathrm{S}-\mathrm{N}$ curve with the $\log N ; m$ is the negative inverse slope of the S-N curve; and $\eta$ is the usage factor given by the Eqn. (8). It's possible to find in the literature several modifications of the Palmgren-Miner rule that have been suggested related to the damage rate and to the strength limits [39].

$$
\eta=\frac{1}{D F F}
$$

where: DFF is the design fatigue factor that can be found in section 6 of the DNVGL-OS-C101 standard [40].

\section{Code's approach}

The S-N curves found in the technical recommendations are expressed in a bi-logarithmic scale, in which the fatigue strength is given by the number of cycles until failure $(N)$ in function with the stress range $(\Delta \sigma)$. Wohler S-N curves consider a global approach and are used in the fatigue design of tubular joints. The fatigue strength in welded joints depends on the member thickness due to local geometric discontinuity in the weld toe in relation to the thickness of the adjacent plates [4]. 
The thickness effect in the fatigue resistance can also be explained with the modification of the stress range in a way that for a higher thickness compared with the referenced thickness, the S-N curve can be obtained through Eqn. (9):

$$
\log N=\log \bar{a}-m \cdot \log \left(\Delta \sigma\left(\frac{t}{t_{r e f}}\right)^{k}\right)
$$

where: $m$ is the negative inverse slope of S-N curve; $\log \bar{a}$ is the interception of the $\log \mathrm{N}$-axis; $t_{r f}$ is reference thickness equal to $25 \mathrm{~mm}$ for welded connections other than tubular joints. For tubular joints the reference thickness is $32 \mathrm{~mm} ; t$ is the thickness through which a crack will most likely grow, $t=t_{r e f}$ is used for thickness less than $t_{r e} ; k$ is the thickness exponent on a fatigue strength, where $\mathrm{k}$ is considered 0.1 for tubular butt welds made from one side and 0.25 for threaded bolts subjected to stress variation in the axial direction.

The S-N curves for the tubular joints considering different environmental conditions are presented in Fig. 4.

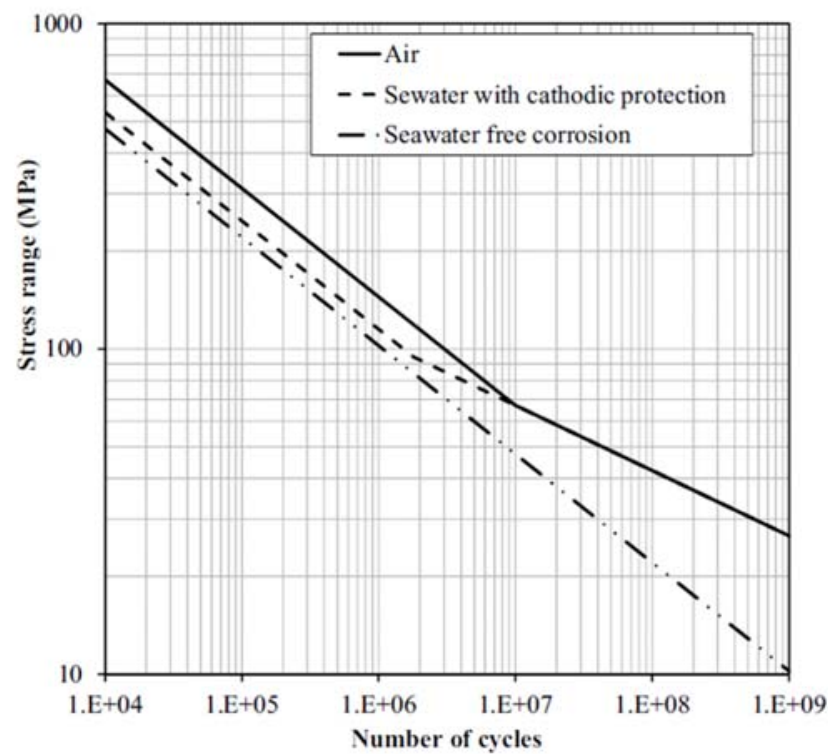

Figure 4: S-N curves for tubular joints in air environment, seawater with cathodic protection and free corrosion [4].

\section{Simplified approach}

The fatigue evaluation in tubular joints is essential to the design of offshore structures. The fatigue results will influence the structure reliability in various aspects but more precisely the residual stresses on a partially damaged structural system [39]. Some principal methodologies will be approached to estimate the fatigue accumulated damage using S-N curves.

The deterministic analysis is based on a limited number of waves with a specified height and period to all fatigue states. The selection of waves is based on the contribution of each sea state in the wave length dispersion diagram. These waves are assessed discretely and are combined such that they have the highest impact on fatigue damage. Each of these specific waves is considered at various wave crest states. These crest wave states are combined in such a way that the maximum and minimum values of stress and consequently the range of stress in the members and joints of the structure are achieved. The fatigue damage ratio can be estimated after evaluating the hot-spot stress according to the number of occurrences of the waves for each period of time and using the Palmgren-Miner rule [41].

To the fatigue damage evaluation, the Weibull distribution of two-parameters is used to analyse the distribution of stresses around the tubular joints. This methodology also uses the Palmgren-Miner rule allied to the S-N curves [4,42]. For continuous stress spectrum cases, the long-term stress range distribution might be defined applying the Weibull distributions for the different load conditions and can be estimated using the following equation:

$$
D=v_{0} T_{d}\left[\frac{q^{m_{1}}}{\bar{a}_{1}} \Gamma\left(1+\frac{m_{1}}{b} ;\left(\frac{s_{1}}{q}\right)^{b}\right)+\frac{q^{m_{2}}}{\bar{a}_{2}} \gamma\left(1+\frac{m_{2}}{b} ;\left(\frac{S_{1}}{q}\right)^{b}\right)\right] \leq \eta
$$


where: $T_{d}$ is the design life in seconds; $v_{0}$ is the average zero up-crossing frequency; $\mathrm{n}$ is the Weibull stress range shape parameters; $\mathrm{q}$ is the Weibull scale distribution parameters; $S_{1}$ is the stress range for which change of slope of S-N curve occur; $\bar{a}_{1}$ and $m_{1}$ are the S-N fatigue parameters for $N<10^{7}$ cycles (air conditions); $\bar{a}_{2}$ and $m_{2}$ are the S-N fatigue parameters for $N>10^{7}$ cycles (air conditions); and, $\Gamma 0$ and $\gamma 0$ are the incomplete gamma functions.

In the long run, the stress distribution in the stress spectrum can be presented as a Weibull distribution of two-parameters:

$$
Q(\Delta \sigma)=\exp \left[-\left(\frac{\Delta \sigma}{q}\right)^{b}\right]
$$

where: $Q$ is the probability of failure in the stress spectrum; $b$ is the Weibull shape parameter; $q$ is the Weibull scale parameter defined from the stress spectrum that can be estimated through:

$$
q=\frac{\Delta \sigma_{0}}{\left(\ln n_{0}\right)^{1 / b}}
$$

Spectral fatigue analysis is used to evaluate the dynamic response of the structure to the wave height range and to the frequencies corresponding to the dispersion diagram. This structural response considerably includes all states of the influence of the waves in the damage caused by fatigue. The spectral dynamic analysis is based on the spectral (wave spectrum) density function in each sea state. Sea waves are then modelled according to the wave dispersion diagram model as a set of sea states. Therefore, in order to create a transfer function for spectral analysis, the expression for the nonlinear drag force in the Morrison equation should be linearized with one of the proposed methods of the regulation such as the use of the steepness of the continuous wave [41].

\section{Spectral approach}

In the simplified fatigue approach, fatigue damage is estimated assuming that the stress follows a Weibull distribution for a long-term response. Due to the sensitivity of the estimated damage to fatigue in the Weibull parameters, the spectral assessment of fatigue has become more popular in offshore structural analysis [39].

The spectral fatigue analysis method recognizes the stochastic nature of the marine environment to which the offshore structures are inserted. The spectral fatigue calculations start from the assumption that there is a relationship between the direction and frequency of the wave and the voltage response at a specific location. The function that performs this correlation is called the transfer function [39].

This technique is complex and numerically intensive, so there is more than one variant of the method that can be validly applied in a specific case. The method is appropriate when there is a linear relationship between the height of the wave and the loads compelled to the structure by the wave. Adaptations were made to the basic method to supply the non-linearities, in these cases, the "Time-Domain Analysis Methods" is used in the evaluation of fatigue due to the limitations of the spectral method [5,39].

When the direction of the wave is considered in the definition of sea states, using the Rayleigh distribution, the accumulated damage for all sea states can be calculated using Eqn. (13).

$$
D=\frac{v_{0} T_{d}}{\bar{a}} \Gamma\left(1+\frac{m}{2}\right)^{\substack{\text { all seastates } \\ \sum_{i=1, j=1}}} r_{i j}\left(2 \sqrt{2 m_{0 i j}}\right)^{m} \leq \eta
$$

where: $r_{i j}$ is the relative number of stress cycles in short-term condition $i, j ; v_{0}$ is long-term average response zero-crossingfrequency; and, $m_{0 i j}$ is zero spectral moment of the stress response process.

\section{Advanced fatigue approaches}

Several fatigue approaches based on local criteria, multiaxial criteria, static toughness, strain energy density, etc. have been proposed [43-56]. Mourão et al. [43] proposed a global-local methodology based on a local approach using the strain fatigue damage parameter to assessing the fatigue damage accumulation. In his scientific work, the proposed methodology was applied for an offshore jacket-type platform [43]. Other approaches has been used to evaluate the fatigue damage 
accumulation based on isodamage curves through the exhaustion of static toughness as suggested by Xia [44], as well as the strain energy density approach applied to ocean systems as proposed by Zarandi and Skallerud [45]. Additionally, a generalized probabilistic model for various fatigue damage variables proposed by Correia et al. [46] can also be used to assessing the fatigue damage accumulation [47].

\section{ANALYSIS AND STRESS CONCENTRATION FACTORS}

\section{$\mathrm{I}$}

Nominal, notch and hot-spot approach $\mathrm{n}$ welded joints, the fatigue strength is estimated through cyclic stress in the point of interest. There are several methods and approaches to determine the S-N curves: nominal, notch, and hot-spot approaches.

In the nominal stress approach, the stresses are estimated without considering any stress concentration due to the local structural detail or due to the weld. This approach has some disadvantages primarily since it is impossible to establish reasonable nominal stress due to complex geometry and to the applied load, and secondly because fatigue strength tests aren't usually available for these types of complex joints in offshore structures [4]. The nominal stress can be determined using elementary theories of structural mechanics based on linear-elastic behaviour:

$$
\sigma_{\text {nom }}=\frac{P}{A} \pm \frac{M}{I} y
$$

where: $P$ is the force acting on cross-section; $A$ is the cross-section area; $M$ is applied bending moment; $I$ is section inertia; and, $y$ is the position of the extreme fibre.

The hot-spot stress approach, different from the nominal stress approach, considers the stress raising effect due to structural discontinuity except the stress concentration due to weld toe, this means without considering the localized weld notch stress [57]. Hot-spot is defined as the region in the joint where fatigue cracks are more susceptible to appear due to cyclic loading, meaning that hot-spot stress is the value of the stress in the surface of the hot-spot. Radaj [58] demonstrated that the hotspot stress corresponds to the sum of the membrane and bending stresses at the weld toe, which can be determined through extrapolation [57,59]. According to DNVGL recommendations, notch stresses must be considered in special cases in which is hard to evaluate with assurance the fatigue strength using other methods. Radaj [58] also demonstrated that the notch stress components can be divided from the non-linear stress: membrane stress $\left(\sigma_{m e m}\right)$, bending stress $\left(\sigma_{b e n}\right)$ and non-linear stress part $\left(\sigma_{n l p}\right)$. The stress distribution through the thickness of the weld plate and its components are shown in Fig. 5.

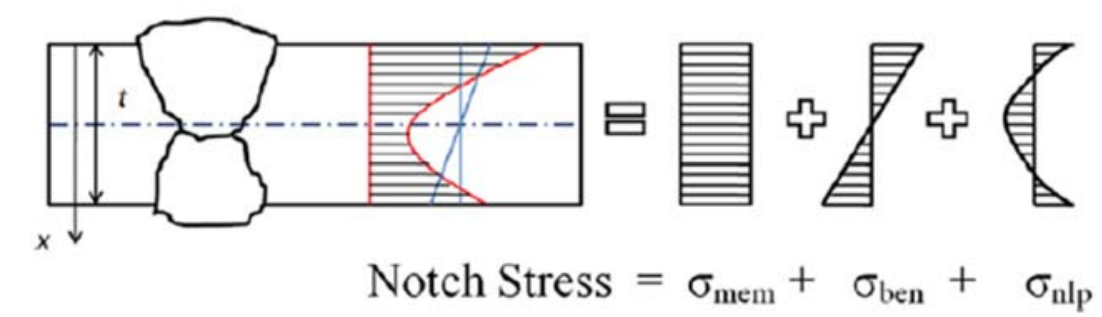

Figure 5: Stress distribution through the thickness of the weld plate and its components [57].

Stress concentration factor

In tubular welded joints when geometry discontinuities are considered, consequently, there are changes in the stress field of these elements. This way, with higher points of stress, the structure is more suitable to fail. Therefore, the stress concentration factor is used to evaluate this concentration ratio and it is defined as the ratio between the hot-spot stress $\left(\sigma_{\text {hot-spot }}\right)$, and the nominal stress $\left(\sigma_{\text {nom }}\right)[4]$.

$$
S C F=\frac{\sigma_{\text {bot-spot }}}{\sigma_{\text {nom }}}
$$

The DNVGL recommendations [4] present different parametric equations to obtain the SCF based on Efthymiou's researches, calculated in different points of the joint connection, taking into consideration different geometrical parameters. The stress concentration factor can be obtained analytically, numerically using the FE method and experimentally [4]. 


\section{FRACTURE MECHANICS APPROACH}

\section{Crack growth due to fatigue}

he fracture mechanics approaches assume that all structural elements have defects and cracks, and, consequently, the design is based on the tolerance to these defects. Thus, fracture mechanics is focused on calculating the number of cycles that a certain critical crack takes to achieve the final failure, in order to evaluate how long a structure or component can operate without having to be fixed [3,60,61].

There are three basic modes of fracture: mode $\mathrm{I}$ is the tensile opening mode and is characterized by the separation of crack faces in the direction perpendicular to the crack plane, mode II is the in-plane shear mode and is the mode in which the crack faces are sheared in the direction parallel to the crack front face, mode III is the transverse shear mode and, similarly to mode II, in this mode, the crack faces are sheared, but this time in the direction perpendicular to the crack front face. The three basic modes of fracture are displayed below, respectively [3,60,62].

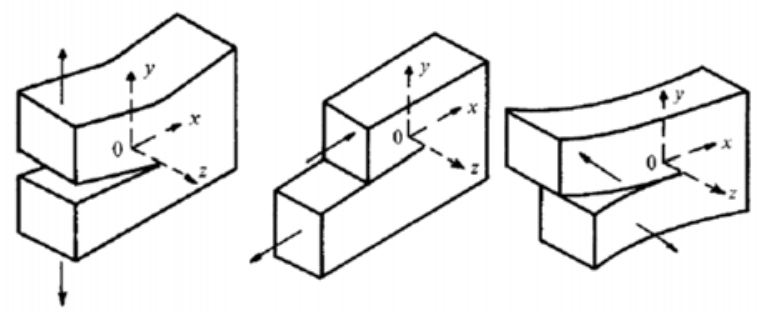

Figure 6: (a) Mode I; (b) Mode II; (c) Mode III [60].

It is assumed that compression doesn't influence crack propagation but since welded joints contain residual stresses, all the stress spectrums must be considered [4]. The crack propagation can be divided into three stages: the first is characterized by considerable low crack growth rates and in this region can be identified a value, known as the threshold, above which there is no crack growth; the second stage is the region known as "Paris region", because the crack growth as a function of stress intensity can be defined by the following expression, which was proposed by Paul Paris:

$$
\frac{d a}{d N}=C(\Delta K)^{m}
$$

where: $d a / d \mathrm{~N}$ is the fatigue crack growth rate; $C$ and $m$ are constants obtained through experimental tests; and $\Delta K$ is the stress intensity factor range $\left(\Delta K=K_{\max }-K_{\min }\right)$. The stress intensity factor, $K$, can be expressed as:

$$
K=\sigma g \sqrt{\pi a}
$$

where: $\sigma$ is the nominal stress on the normal member to the crack; $g$ is the factor depending on the member geometry, weld, and crack geometry; and, $a$ is the depth of the crack. The third phase is the last phase and is characterized by an unstable crack growth until the total failure.

Several studies to characterize the fatigue crack propagation behaviour considering corrosion [63], variable amplitude loading [64], crack closure effects [65], mixicity conditions [66], as well as, using local approaches [67,68, have been suggested.

\section{Evaluation of the residual lifetime of structural components}

The availability of accurate fatigue crack propagation laws is the key to reliable fatigue life predictions of mechanical components or structural details. The most common use of the fracture mechanics based on fatigue crack propagation relations consists of residual fatigue life assessment of mechanical components or structural details containing initial known defects acting like cracks. This can be accomplished by integrating the crack propagation law, according to the following expression: 


$$
\frac{d a}{d N}=f(\Delta K, R, \ldots) \rightarrow N_{f}=\int_{a_{i}}^{a_{f}} \frac{d a}{f(\Delta K, R, \ldots)}
$$

The main difficulty implied in this approach is the determination of the initial crack size for the crack growth analysis. One practical solution is using an empirically assumed crack length, such as $0.15-1 \mathrm{~mm}$ for metals whereby the assumption of such macro-crack could underestimate the fatigue life of the component. Aeran et al. [69] suggested a framework to assess structural integrity of ageing offshore jacket structures for fatigue life extension.

For situations in which crack growth near the threshold is significant, a less conservative form of Paris law based on the effective value of $\Delta K, \Delta K_{e f f}$, may be justified. In these circumstances, the relevant equation is the following:

$$
\begin{aligned}
& \frac{d a}{d N}=C\left(\Delta K_{e f f}\right)^{m} \\
& \Delta K_{e f f}=\frac{\Delta K-\Delta K_{0}}{1-R} \\
& \int_{a_{i}}^{a_{f}}\left(\frac{1-R}{\sigma g \sqrt{\pi a}-\frac{\Delta K}{\Delta \sigma}}\right)^{m} d a=C(\Delta \sigma) N
\end{aligned}
$$

where, $C$ and $m$ are constants which depend on the material and the applied conditions, including environment and cyclic frequency. For $\Delta K \leq \Delta K_{0}, d a / d N$ is assumed to be zero.

\section{CONCLUSION}

A $\mathrm{n}$ offshore wind turbine support structure can be exposed to various factors that carry fatigue damage. The phenomenon of fatigue is one of the main causes of structural failure, which consists of the loss of strength due to the appearance of cracks in an element subjected to cyclic or dynamic loading. Understanding the fatigue design phases, criteria and existing approaches is, therefore, of extreme importance for an effective and clear design of an offshore wind turbine support structure. In this paper, a brief overview of the fatigue design criteria and some advanced approaches that have been used in the assessment and analysis of support structures for oceanic systems are presented.

\section{ACKNOWLEDGEMENTS}

$\mathrm{T}$ his work was financially supported by: Base Funding - UIDB/04708/2020 and Programmatic Funding UIDP/04708/2020 of the CONSTRUCT - Instituto de I\&D em Estruturas e Construções - funded by national funds through the FCT/MCTES (PIDDAC). Additionally, this research was also supported by the project grant (UTA-EXPL/IET/0111/2019) SOS-WindEnergy - Sustainable Reuse of Decommissioned Offshore Jacket Platforms for Offshore Wind Energy by national funds (PIDDAC) through the Portuguese Science Foundation (FCT/MCTES). This research study was also supported by the CAPES - PRINT Program (Coordination for the Improvement of Personnel of Graduation) and UFMG (Universidade Federal de Minas Gerais).

\section{REFERENCES}

[1] Ju, S.H., Su, F.C., Ke, Y.P., Xie M.H. (2019). Fatigue design of offshore wind turbine jacket-type structures using a parallel scheme. Renewable Energy, 136, pp. 69-78. 
[2] Mendes, P., Correia, J.A.F.O., Mourão, A., Pereira, R., Fantuzzi, N., De Jesus, A. and Calçada, R. (2021). Fatigue Assessments of a Jacket-Type Offshore Structure Based on Static and Dynamic Analyses. Practice Periodical on Structural Design and Construction, 26(1), 04020054.

[3] Dantas, R.G. (2019). Fatigue life estimation of steel half-pipes bolted connections for onshore wind towers applications. MSc Thesis, University of Porto, Porto, Portugal, 183 p.

[4] DNV GL Group. DNVGL-RP-C203 (2016). Fatigue design of offshore steel structures.

[5] API. Recommended practice for geotechnical and foundation design considerations. RP 2GEO. Washington, D.C.: American Petroleum Institute; (2011).

[6] Dong, W.B., Moan, T., Gao, Z. (2011). Long-term fatigue analysis of multi-planar tubular joints for jacket-type offshore wind turbine in time domain. Engineering Structures, 33, pp. 2002-2014.

[7] Dong, W.B., Moan, T., Gao, Z. (2012). Fatigue reliability analysis of the jacket support structure for offshore wind turbine considering the effect of corrosion and inspection. Reliability Engineering and System Safety, 106, pp. 11-27.

[8] Alati, N., Nava, V., Failla, G., Arena, F., Santini, A. (2014). On the fatigue behavior of support structures for offshore wind turbines. Wind and Structures, 18, pp. 117-134.

[9] Yeter, B., Garbatov Y., Guedes Soares, C. (2014). Fatigue damage analysis of a fixed offshore wind turbine supporting structure. Book: Developments in Maritime Transportation and Exploitation of Sea Resources, pp. 415-424.

[10] Colone, L., Natarajan, A., Dimitrov, N. (2018). Impact of turbulence induced loads and wave kinematic models on fatigue reliability estimates of offshore wind turbine monopiles. Ocean Engineering, 155, pp. 295-309.

[11] Biswal, R., Mehmanparast, A. (2019). Fatigue damage analysis of offshore wind turbine monopile weldments. Procedia Structural Integrity, 17, pp. 643-650.

[12] Chian, C.Y., Zhao, Y.Q., Lin, T.Y., Nelson, B., Huang H.H. (2018). Comparative Study of Time-Domain Fatigue Assessments for an Offshore Wind Turbine Jacket Substructure by Using Conventional Grid-Based and Monte Carlo Sampling Methods. Energies, 11, p.3112.

[13] Peeringa, J.M. (2014). Fatigue loading on a 5MW offshore wind turbine due to the combined action of waves and current. Journal of Physics: Conference Series, 524.

[14] Teixeira, R., O’Connor, A., Nogal, M., Krishnan, N., Nichols, J. (2017). Analysis of the design of experiments of offshore wind turbine fatigue reliability design with Kriging surfaces. Procedia Structural Integrity, 5, pp. 951-958.

[15] Horn, J.T., Leira B.J. (2019). Fatigue reliability assessment of offshore wind turbines with stochastic availability. Reliability Engineering and System Safety, 191, 106550.

[16] Rocher, B., Schoefs, F., François, M., Salou, A., Caouissin, A.L. (2020). A two-scale probabilistic time-dependent fatigue model for offshore steel wind turbines. International Journal of Fatigue, 136, 105620.

[17] Li, X. and Zhang, W. (2020). Long-term fatigue damage assessment for a floating offshore wind turbine under realistic environmental conditions. Renewable Energy, 159, pp. 570-584.

[18] Luna, J., Falkenberg, O., Gros, S. and Schild, A. (2020). Wind turbine fatigue reduction based on economic-tracking NMPC with direct ANN fatigue estimation. Renewable Energy, 147, pp. 1632-1641.

[19] Ju, S., Su, F., Ke, Y. and Xie, M. (2019). Fatigue design of offshore wind turbine jacket-type structures using a parallel scheme. Renewable Energy, 136, pp. 69-78.

[20] Pereira, R.R. B. Dynamic Analysis and Fatigue Assessment of a Jacket-Type Offshore Platform. MSc Thesis, University of Bologna, Italy, $112 \mathrm{p}$.

[21] Chakrabarti, S. Handbook of Offshore Engineering. Elsevier, (2005).

[22] European Wind Energy Association: Deep Water: The Next Step for Offshore Wind Energy. Brussels, Belgium: A report by the European Wind Energy Association; (2013).

[23] Mendes, P. (2018). Stress concentration factor evaluation in offshore tubular KT-joints for fatigue design. MSc Thesis, University of Porto, Porto, Portugal, 120 p.

[24] DNV GL Group. DNV-RP-C205 (2010). Environmental Conditions and Environmental Loads.

[25] Liu, X., Lu, C., Li, G., Godbole, A., Chen, Y. (2017). Effects of aerodynamic damping on the tower load of offshore horizontal axis wind turbines. Applied Energy, 204, pp. 1101-1114.

[26] Liu, X., Zhang, X., Li, G., Chen, Y., Ye, Z. (2010). Dynamic response analysis of the rotating blade of horizontal axis wind turbine, Wind Engineering, 34, pp. 543-560.

[27] Li, L; Liu Y; Yuan, Z; Gao, Y. (2018) Wind field effect on the power generation and aerodynamic performance of offshore floating wind turbines. Energy, 157, pp. 379-390.

[28] Skjelbreia, L; Hendrickson, J. (2011) Fifth order gravity wave theory. Engineering Proceedings, 7.

[29] Fenton, J. (1990). Nonlinear wave theories. The Sea, 9, pp. 3-25. 
[30] Xu, K., Zhang, M., Shao, Y., Gao, Z., Moana, T. (2019). Effect of wave nonlinearity on fatigue damage and extreme responses of a semi-submersible floating wind turbine. Applied Ocean Research, 91, 101879.

[31] Cheng, D., Gao, P., Huang, S., Li, C., Yu, X. (2020). Static and dynamic loading behavior of a hybrid foundation for offshore wind turbines. Marine Structures, 71, 102727.

[32] Marino, E., Giusti, A., Manuel, L. (2017). Offshore wind turbine fatigue loads: The influence of alternative wave modeling for different turbulent and mean winds. Renewable Energy, 102, pp. 157-169.

[33] Chen, P., Huang, Y., Wan, D. (2019). A numerical model for fully coupled aero-hydrodynamic analysis of floating. Ocean Engineering, 173, pp. 183-196.

[34] Li, H., Du, J., Wang, S., Sun, M., Chang, A. (2016). Investigation on the probabilistic distribution of mooring line tension for fatigue damage assessment. Ocean Engineering, 124, pp. 204-214.

[35] BMT Fleet Technology, (2013). Fatigue Design Review of Offshore Wind Turbine Generator Structures.

[36] Prabhakar, S., Goswami G. (2019). Design, management and key success factors of an offshore cathodic protection system for corrosion control. International Journal of Engineering and Management, 9, pp. 171-179.

[37] Bhandari, J., Khan F., Abbassi R., Garaniya V., Ojeda R (2015). Modelling of pitting corrosion in marine and offshore steel structures - A technical review. Journal of Loss Prevention in the Process Industries, 37, pp. 39-62.

[38] Miner M.A. (1945). Cumulative damage in fatigue. Transactions of the ASME. Series E. J. Appl. Mech., 12, pp.159164.

[39] Bai Y. (2003) Marine Structural Design, Elsevier, 634 p.

[40] DNV GL Group. DNVGL-OS-C101 (2015). Design of offshore steel structures, general - LRFD method.

[41] Havigh S.N., Askar M.B. (2017). The Process of Fatigue Analysis on Fixed Metal Offshore Platforms. Scientifc \& Academic 7, pp. 10-16.

[42] Mourão A. (2018). Fatigue analysis of a jacket-type offshore platform based on local approaches. MSc Thesis, University of Porto, Porto, Portugal, 139 pages.

[43] Mourão, A., Correia, J.A.F.O., Ávila, B.V., De Oliveira, C.C., Ferradosa, T., Carvalho, H., Castro, J.M. and De Jesus, A.M.P. (2020). A fatigue damage evaluation using local damage parameters for an offshore structure. Proceedings of the Institution of Civil Engineers: Maritime Engineering, 173(2), pp. 43-57.

[44] Xia, F.-., Zhu, S.-., Liao, D., Dantas, R., Correia, J.A.F.O. and De Jesus, A.M.P. (2020). Isodamage curve-based fatigue damage accumulation model considering the exhaustion of static toughness. Engineering Failure Analysis, $115,104575$.

[45] Zarandi, E.P. and Skallerud, B.H. (2020). Cyclic behavior and strain energy-based fatigue damage analysis of mooring chains high strength steel. Marine Structures, 70, 102703.

[46] Correia, J., Apetre, N., Arcari, A., De Jesus, A., Muñiz-Calvente, M., Calçada, R., Berto, F. and Fernández-Canteli, A. (2017). Generalized probabilistic model allowing for various fatigue damage variables. International Journal of Fatigue, 100, pp. 187-194.

[47] Fernández-Canteli, A., Blasón, S., Correia, J.A.F.O. and De Jesus, A.M.P. (2014). A probabilistic interpretation of the miner number for fatigue life prediction. Frattura ed Integrita Strutturale, 30, pp. 327-339.

[48] Ayatollahi, M.R., Rashidi Moghaddam, M., Razavi, S.M.J. and Berto, F. (2016). Geometry effects on fracture trajectory of PMMA samples under pure mode-I loading. Engineering Fracture Mechanics, 163, pp. 449-461.

[49] Berto, F. and Lazzarin, P. (2013). Multiparametric full-field representations of the in-plane stress fields ahead of cracked components under mixed mode loading, International Journal of Fatigue, 46, pp. 16-26.

[50] Ferro, P., Lazzarin, P. and Berto, F. (2012). Fatigue properties of ductile cast iron containing chunky graphite, Materials Science and Engineering A, 554, pp. 122-128.

[51] Zhu, S.-., Yu, Z.-., Correia, J., De Jesus, A. and Berto, F. (2018). Evaluation and comparison of critical plane criteria for multiaxial fatigue analysis of ductile and brittle materials, International Journal of Fatigue, 112, pp. $279-288$.

[52] Torabi, A.R., Campagnolo, A. and Berto, F. (2015). Local strain energy density to predict mode II brittle fracture in Brazilian disk specimens weakened by V-notches with end holes, Materials and Design, 69, pp. 22-29.

[53] Berto, F., Gallo, P. and Lazzarin, P. (2014). High temperature fatigue tests of un-notched and notched specimens made of 40CrMoV13.9 steel, Materials and Design, 63(1), pp. 609-619.

[54] Berto, F., Lazzarin, P. and Kotousov, A. (2011). On higher order terms and out-of-plane singular mode, Mechanics of Materials, 43(6), pp. 332-341.

[55] Berto, F., Lazzarin, P. and Wang, C.H. (2004). Three-dimensional linear elastic distributions of stress and strain energy density ahead of $\mathrm{V}$-shaped notches in plates of arbitrary thickness, International Journal of Fracture, 127(3), pp. 265282.

[56] Wu, W., Hu, W., Qian, G., Liao, H., Xu, X. and Berto, F. (2019). Mechanical design and multifunctional applications of chiral mechanical metamaterials: A review, Materials and Design, 180, 107950. 
[57] Saini, D. S., Karmakar, D., Ray-Chaudhuri, S. (2016). A review of stress concentration factors in tubular and nontubular joints for design of offshore installations. Journal of Ocean Engineering and Science 3, 186-202.

[58] Radaj, D. (1990). Design and Analysis of Fatigue Resistant Welded Structures, Cambridge: Abington Publisher.

[59] Shabakhty, N., Haselibozchaloee, D., Correia, J.A.F.O. (2021). Investigation on fatigue damage calibration factors of steel members in offshore structures. Proceedings of the Institution of Civil Engineers: Maritime Engineering, DOI: $10.1680 /$ jmaen.2020.17

[60] Suresh, S. (1998). Fatigue of Materials. Cambridge University Press, New York.

[61] Xin, H., Correia, J.A.F.O., Veljkovic, M. (2021). Three-dimensional fatigue crack propagation simulation using extended finite element methods for steel grades S355 and S690 considering mean stress effects. Engineering Structures, 227, 111414.

[62] Fernandes, A., de Castro, P., Moura Branco, C. (1999). Fadiga de Estruturas Soldadas. Fundacão Calouste Gulbenkian, Lisboa (in Portuguese).

[63] Jacob, A., Mehmanparast, A. (2021). Crack growth direction effects on corrosion-fatigue behaviour of offshore wind turbine steel weldments. Marine Structures, 75, 102881.

[64] Correia, J., Carvalho, H., Lesiuk, G., Mourão, A., Grilo, L.F., de Jesus, A., Calçada, R. (2020) Fatigue crack growth modelling of Fão Bridge puddle iron under variable amplitude loading. International Journal of Fatigue, 136, 105588.

[65] Correia, J.A.F.O., Blasón, S., Arcari, A., Calvente, M., Apetre, N., Moreira, P.M.G.P., De Jesus, A.M.P., Canteli, A.F. (2016). Modified CCS fatigue crack growth model for the AA2019-T851 based on plasticity-induced crack-closure. Theoretical and Applied Fracture Mechanics, 85, pp. 26-36.

[66] Silva, A.L.L., de Jesus, A.M.P., Xavier, J., Correia, J.A.F.O., Fernandes, A.A. (2017). Combined analytical-numerical methodologies for the evaluation of mixed-mode (I+II) fatigue crack growth rates in structural steels. Engineering Fracture Mechanics, 185, pp. 124-138.

[67] Correia, J.A.F.O., de Jesus, A.M.P., Fernández-Canteli, A. and Calçada, R.A.B. (2015). Modelling probabilistic fatigue crack propagation rates for a mild structural steel. Frattura ed Integrita Strutturale, 31, pp. 80-96.

[68] Huffman, P.J., Ferreira, J., Correia, J.A.F.O., De Jesus, A.M.P., Lesiuk, G., Berto, F., Fernández-Canteli, A. and Glinka, G. (2017). Fatigue crack propagation prediction of a pressure vessel mild steel based on a strain energy density model. Frattura ed Integrita Strutturale, 11(42), pp. 74-84.

[69] Aeran, A., Siriwardane, S.C., Mikkelsen, O. and Langen, I. (2017). A framework to assess structural integrity of ageing offshore jacket structures for life extension. Marine Structures, 56, pp. 237-259. 